\title{
Study of cardiac disease and its outcome in pregnancy
}

\author{
Tejal L. Patel, Kritika S. Pandey*, Arvind Ambaliya
}

Department of Obstetrics and Gynecology, Civil Hospital, B. J. Medical College, Ahmedabad, Gujarat, India

Received: 07 November 2018

Accepted: 04 December 2018

\section{*Correspondence:}

Dr. Kritika S. Pandey,

E-mail: pandeykritika081@gmail.com

Copyright: (c) the author(s), publisher and licensee Medip Academy. This is an open-access article distributed under the terms of the Creative Commons Attribution Non-Commercial License, which permits unrestricted non-commercial use, distribution, and reproduction in any medium, provided the original work is properly cited.

\begin{abstract}
Background: Pregnancy comes as a temporary complication in the disease process of a patient with a cardiac lesion. It is the $4^{\text {th }}$ common cause of maternal mortality and one of the most important non-obstetrical causes of maternal death. Previously most women with diagnosed heart disease were advised to avoid pregnancy and labor and termination was advised. But in modern obstetrical practice, pregnancy in a patient with a heart disease is no longer an unacceptable hazard. The objective of this study is to find out incidence of cardiac diseases in pregnancy, to evaluate their management and to find out maternal and fetal outcome in pregnancy with cardiac disease.

Methods: This study is a prospective cohort study in which an analysis of maternal and fetal outcome in 30 cases of cardiac diseases in pregnancy was carried out in the department of Obstetrics and Gynaecology in our institute at Civil hospital Ahmadabad from 01/01/2017 to 31/12/2017.The study included all known case of RHD, CHD, or newly diagnosed case or surgically corrected case with prosthetic heart valves during current pregnancy.

Results: Majority of women having pregnancy with cardiac disease were in the age group of 20-30 years. Majority of them were primigravida and suffered from rheumatic heart diseases with grade 1 NYHA severity. Majority of women got delivered by normal vaginal delivery with healthy fetal outcome. Most of the babies born to cardiac mother had their baby weight ranging between $2.0-2.5 \mathrm{~kg}$.

Conclusions: The results of present study indicate that heart disease forms a considerable proportion of medical illness complicating pregnancy. Cardiac disease presents problems both to the obstetrician and as well as to the physician, cardiologist and to the neonatologist. But the majority of pregnancies complicated by heart disease are uneventful with a favorably good outcome for both the mother and the fetus.
\end{abstract}

Keywords: Congenital heart disease, Congestive cardiac failure, Postpartum intrauterine contraceptive device

\section{INTRODUCTION}

Pregnancy comes as a temporary complication in the disease process of a patient with a cardiac lesion. Prevalence of heart disease in pregnancy varies from $0.3 \%-3.5 \%{ }^{1-3}$ It is the fourth common cause of maternal mortality and one of the most important non-obstetrical cause of maternal death. ${ }^{4,5}$ Previously most women with diagnosed heart disease were advised to avoid pregnancy and were counseled for termination. But in modern obstetrical practice, pregnancy in a patient with heart disease is no longer an unacceptable hazard. Joint management between the obstetrician and the cardiologist has improved the outcome of pregnancy and has reduced the maternal risks. ${ }^{7}$

Disease pattern varies widely when developed and underdeveloped countries are compared (Uelen and Glechen 1982). In U.S.A. and Western Europe incidence of RHD has declined. In India and Nigeria acute and chronic RHD still constitutes a major health problem among pregnant women. ${ }^{8}$ Though heart disease is often a worrying problem, the study shows that outcome of pregnancy is generally satisfactory and majority of the 
patients with proper management achieve normal vaginal delivery after spontaneous onset of labour. The aims and objectives of this study are to find out incidence of various cardiac diseases in pregnant women in a tertiary care center, evaluate causes and management of heart disease with pregnancy, to find out causes leading to cardiac decompensation and possible prophylactic measures, to assess maternal and fetal outcome and prognosis.

\section{METHODS}

This study is a Prospective Cohort Study in which an analysis of maternal and fetal outcome in 30 cases of cardiac disease in pregnancy was carried out in the department of Obstetrics and Gynecology in our institute at Civil Hospital Ahmedabad from 01/01/2017 to $31 / 12 / 2017$. Data were collected in a pre- designed form. No data or any information was collected without permission of patient, participation in this research was fully voluntary. All data were analyzed by using computer based Statistical Package for Social Science (SPSS 16) programmed. Statistical analysis was performed, categorical variables was presented in the form of frequency and percentage.

\section{Inclusion criteria}

- Patients who were known case of RHD or diagnosed during present pregnancy

- Patients with congenital heart disease

- Patients with prosthetic heart valves and surgically corrected heart disease.

\section{RESULTS}

Total 30 cases of pregnancy with cardiac disease out of 9439 deliveries during period from 01/01/2017 to $31 / 12 / 2017$ were studied in terms of maternal and fetal outcomes. Total 9439 patients were registered as indoor patients at our setup during the study period. Prevalence of cardiac disease during the study was $0.32 \%$ (3.2 cases per 1000 deliveries). This study was conducted at our hospital and the obstetric and fetal outcome of 30 patients with heart disease was studied during my residency. In addition to routine antenatal workup, cardiologists decided type and severity of cardiac lesion and also evaluated patient with heart disease.

In present study 19(65\%) were emergency cases which were referred from outside because CHA being a tertiary care center and $11(35 \%)$ cases were already booked in ANC OPD and were knowing about their ailment and were under regular treatment of physician and cardiologist.

Below is the table showing type of heart disease with etiological distribution. RHD still constitutes the major group of heart disease in pregnancy, especially in the developing countries. In present series Table 1 shows
RHD consisted 20 out of 30 cases which account for $66.7 \%$.

Various authors ranging from $4 \%$ to $8 \%$ have described the proportion of CHD. In this study Table 1 shows that CHD constitutes $30.98 \%$ of total cases of heart disease may be due to easy availability of diagnostic techniques like 2D-Echo. So, trivial conditions like bicuspid aortic valves and mitral valve prolapse have also been increasingly recognized in minimally symptomatic patients.

\section{Table 1: Etiological distribution.}

\begin{tabular}{|l|l|l|}
\hline Type of cardiac disease & No. of cases & $\%$ \\
\hline Rheumatic heart disease & 20 & 66.7 \\
\hline Cardiomyopathy & 01 & 3.3 \\
\hline Atrial septal defects & 04 & 13.3 \\
\hline Patent ductus arteriosus & 01 & 3.3 \\
\hline Tetralogy of Fallot & 02 & 6.7 \\
\hline Mitral valve prolapse & 01 & 3.3 \\
\hline Bicuspid aortic valves & 01 & 3.3 \\
\hline Total & 30 & 100 \\
\hline
\end{tabular}

Table 2 shows there were 18 primi gravidae, 08 second gravidae, 02 third gravidae and 02 multigravidae patients. Probably parity has no adverse effect on heart diseases (Pinto Rosurio 1975).

Table 2: Relationship of gravidity with heart disease.

\begin{tabular}{|l|l|l|l|l|l|}
\hline Gravidity & RHID & CHID & PPCM & Others & Total \\
\hline Primi & 12 & 05 & 00 & 01 & 18 \\
\hline $2^{\text {nd }}$ & 05 & 01 & 01 & 01 & 08 \\
\hline $3^{\text {rd }}$ & 02 & 00 & 00 & 00 & 02 \\
\hline $4^{\text {th }}$ & 01 & 01 & 00 & 00 & 02 \\
\hline Total & 20 & 07 & 01 & 02 & 30 \\
\hline
\end{tabular}

Table 3 shows most of the patients were in Grade I and II of NYHA classification. With proper care and management normal labor and delivery were achieved in most of these patients. The patients of Grade III and IV were immediately hospitalized because as the grade increases, the maternal and fetal prognosis worsens. In present study out of 30 patients, $26(86.7 \%)$ patients had full term deliveries while 04 (13.3\%) patients had preterm deliveries.

Table 3: Occurrence of severity of heart disease (NYHA grading).

\begin{tabular}{|l|l|l|}
\hline Grade & No. of patients & Percentage \\
\hline I & 18 & 60 \\
\hline II & 09 & 30 \\
\hline III & 01 & 3.3 \\
\hline IV & 02 & 6.7 \\
\hline
\end{tabular}

The patients with heart disease normally have spontaneous normal vaginal delivery in most of the cases. 
In present study $36.7 \%$ had normal vaginal delivery and $56.7 \%$ had LSCS (Table 4).

Table 4: Mode of deliveries.

\begin{tabular}{|l|l|l|}
\hline Mode of Delivery & $\begin{array}{l}\text { No. of } \\
\text { patients }\end{array}$ & $\%$ \\
\hline Vaginal Delivery & 11 & 36.7 \\
\hline LSCS & 17 & 56.7 \\
\hline Forceps assisted vaginal delivery & 02 & 6.6 \\
\hline
\end{tabular}

The indications of the cesarean were most of the time due to cardiac indication (Table 5).

Table 5: Indications of LSCS.

\begin{tabular}{|l|l|}
\hline Indication & No. of patients \\
\hline Malpresentation & 01 \\
\hline Fetal Distress & 01 \\
\hline Cardiac & 08 \\
\hline IUGR & 01 \\
\hline Prev CS & 06 \\
\hline Total & 17 \\
\hline
\end{tabular}

Table 6 shows that total 06 patients developed complications. Out of 30 cases 04 developed CCF, pleural effusion and pulmonary edema.

Table 6: Occurrence of various complications.

\begin{tabular}{|c|c|c|}
\hline Complications & $\begin{array}{l}\text { Rheumatic } \\
\text { heart disease }\end{array}$ & $\begin{array}{l}\text { Congenital } \\
\text { heart disease }\end{array}$ \\
\hline $\begin{array}{l}\text { Congestive cardiac } \\
\text { failure }\end{array}$ & 01 & 01 \\
\hline Pneumonia & - & - \\
\hline Pleural effusion & 02 & 01 \\
\hline Pulmonary edema & 01 & 01 \\
\hline Thromboembolism & 01 & - \\
\hline Maternal mortality & 01 & 01 \\
\hline Hematuria & - & 01 \\
\hline Wound gap & 01 & - \\
\hline
\end{tabular}

2 maternal mortalities occurred- both due to acute cardiorespiratory arrest with cardiogenic shock with severe pulmonary hypertension.

No patient developed acute rheumatic fever probably due to improved and regular prophylaxis by Inj. Benzathin Penicillin 1.2 MU IM every 21 days which is very effective drug in preventing attacks of rheumatic fever.

Most of the patients who developed complications belonged to NYHA grade 3 to 4 from the very beginning and thus this shows that as the functional grade increases the incidence of cardiac decompensation also increases. The fetal outcome in RHD (especially with corrected valvular pathology) is usually good and only a little different from those in patients who don't have heart disease.
As shown in Table 7, 50\% of babies were healthy. It also shows that $43.3 \%$ had low birth weight. Thus, prematurity is very common in patients with heart disease and this in turn leads to babies who are more prone to hypothermia and septicemia.

Table 7: Fetal outcome.

\begin{tabular}{|l|l|l|}
\hline Outcome & No. & $\%$ \\
\hline Healthy & 15 & 50 \\
\hline Intra-uterine growth restriction & 01 & 3.3 \\
\hline Low birth weight & 13 & 43.7 \\
\hline Neonatal intensive care unit admission & 05 & 16.6 \\
\hline Neonatal death & 02 & 6.7 \\
\hline
\end{tabular}

There was not a single case of postdatism in the study. In this study as per Table 8 we had $17 \%$ of babies who had weight less than $=<2 \mathrm{~kg}$ and $47 \%$ had weight between 2.1 to $3 \mathrm{~kg}$. Thus total $62 \%$ babies were of low birth weight in this study. Only 01 baby had birth weight more than $3 \mathrm{~kg}$. This indicates that patients with heart disease normally deliver a baby having birth weight slightly less than that of the other normal pregnant patients.

Table 08: Weight of newborn.

\begin{tabular}{|l|l|l|}
\hline Weight $(\mathrm{kg})$ & Number of newborn & $\%$ \\
\hline$\leq 2$ & 05 & 16.67 \\
\hline $2.1-2.5$ & 14 & 46.67 \\
\hline $2.6-3.0$ & 10 & 33.33 \\
\hline$>3$ & 01 & 3.33 \\
\hline Total & 30 & 100 \\
\hline
\end{tabular}

The incidence of maternal mortality from $0.6 \%$ to $8 \%$ by various authors has been reported. In this study out of 30 cases 02 maternal mortalities reported. Thus, we had case fatality ratio of $6.67 \%$.

Table 9: Contraception.

\begin{tabular}{|l|l|}
\hline Contraception Method & No. of patients \\
\hline Barrier & 18 \\
\hline PPIUCD & 05 \\
\hline Per Op TL & 1 \\
\hline
\end{tabular}

With improvement in the available medical care, proper and well facilitated ICCU, the care of the patient with heart disease should not be a major problem for the modern obstetrician and cardiologist. In present study in Table 918 cases were advised for barrier contraceptives as they are the safest contraceptives in cardiac patients. In 05 patients with corrected valvular heart diseases, with normal cardiac function and taking regular penicillin prophylaxis, postpartum IUCD CuT 380 A insertion was done with all aseptic precautions and were advised for follow up after 6 weeks and explained all the warning symptoms. 1 per op TL was done while performing cesarean section. 


\section{DISCUSSION}

Pregnancy contributes to significant hemodynamic changes i.e. $30-50 \%$ increase in cardiac output, stroke volume and intravascular blood volume. Also, there is $15-25 \%$ increase in heart rate. All these changes can lead to cardiac decompensation in cardiac patients. The obstetrician is the key person responsible for the health of mother and the infant during the pregnancy and delivery. If pregnancy is complicated by heart disease, inter disciplinary approach and regular supervision of the patient during pregnancy can achieve best results. ${ }^{1}$ The present study reflects the fetomaternal outcome of cardiac disease in pregnancy in our hospital, a tertiary care centre in Uttarakhand. In present study prevalence of heart disease is $0.32 \%$. The incidence of registered patients is $35.22 \%$ and emergency cases referred from outside were $64.78 \%$. Thus, being a tertiary care center most of the cases were referred from outside.

RHD is still a major group of heart disease in pregnancy among which mitral valve disease is the commonest.2 RHD constituted $66.7 \%$ cases of all cardiac diseases during present study. Various authors have reported proportion of RHD from $60 \%$ by McFaul et al to $95 \%$ by Dumir andSethi et al (1983). In US and Western Europe the incidence of RHD has shown a declining trend over the last few decades. In India and other developing countries RHD still constitutes a major health problem amongst pregnant women. The contributing factors being low socio-economic status, overcrowding in the houses, illiteracy and limited access to medical care. ${ }^{2,3}$

The majority of the patients were of age $<30$ years of age and among them most were between 21-25 years of age .Majority of the patients were primigravida as they are being counseled regarding the risk of maternal morbidity and mortality in subsequent pregnancies.

It is important to grade the patients under NYHA classification for proper management and conduct, grade III and IV patients need immediate admission and also fetal and maternal outcome worsen in them. But in present study most of them fall under Grade I (18 patients) and Grade II (09 patients).

Antibiotics prophylaxis is must in all cases of RHD for prevention of infective endocarditis. Out of 20 cases of RHD, all were taking Penicillin prophylaxis already and they were advised to continue the same. So, as a result not a single patient presented with a rheumatic fever nor developed during their period of hospitalization.

Heart disease patients normally have spontaneous vaginal delivery but in present study $36.7 \%$ patients had normal vaginal deliveries and $56.7 \%$ had LSCS for cardiac indications while $6.6 \%$ underwent instrumental (ventouse/forceps) vaginal deliveries. ${ }^{9}$ Cardiac failure, pleural effusion AND pulmonary edema developed in total 6 cases $(20 \%)$. Out of 6 cases 2 cases already presented to us with complications, 1 at 35 weeks of gestation and the other with 30-32 weeks of gestation. 1 patient developed acute CHF and pulmonary edema while doing cesarean section and 1 developed after 6 days of postpartum period. These patients required intensive care monitoring immediately.

Fetal outcome in cardiac patients is usually good and only a little different from those patients who do not suffered from heart disease. ${ }^{10-15} 13.3 \%$ of patients in present study had preterm deliveries thus preterm labor is common in patients with cardiac diseases. Not a single patient had postdatism. $43.6 \%$ of the babies were of low birth weight and most of the babies weighed between 2.0$2.5 \mathrm{~kg}$ and there was 01 IUGR $(3.33 \%)$ baby. It was noted that the furosemide and digoxin given to the patients of heart disease do not cause any harm to the fetus.

Throughout the study 02 maternal mortalities occurredboth due to acute cardiorespiratory arrest with cardiogenic shock with severe pulmonary hypertension. Thus, making case fatality ratio of $6.67 \%$. Also 02 neonatal mortality noted contributing $6.7 \%$ cases. Thus, majority of pregnancies complicated by heart disease in this study had uneventful course with favorable maternal and fetal outcome.

The patient of heart disease should be explained the risk of oral contraceptives like thromboembolic diseases, hypertension, hyperlipidemia etc. which can further aggravate her ailments. The intrauterine device is included in WHO category II medical criteria and can lead to infection and subsequent endocarditis in damaged heart. The conventional barrier form of contraception like condom, diaphragm and foam are safe in all patients however their low efficiency must be considered while recommending them. ${ }^{15,16}$ Barrier contraception should be the ideal choice for these patients, but modern CuT-380 A can also be used when benefits outweigh risks as stated by WHO (medical eligibility criteria category II).

\section{CONCLUSION}

The results of present study indicate that heart disease forms a considerable proportion of medical illness complicating pregnancy.

Cardiac disease presents problems both to the obstetrician and as well as to the physician, cardiologist and to the neonatologist. But the majority of pregnancies complicated by heart disease are uneventful with a favourably good outcome for both the mother and the fetus.

The time to learn about the safety or hazards of pregnancy in such patients is prior to pregnancy. The management includes intensive care throughout pregnancy and also during labor and postpartum. The earliest signs of complication need to be watched for 
vigilance with combined efforts from the obstetrician, a physician and a cardiologist and is mandatory for successful course and outcome of pregnancies complicated by heart diseases.

The newer investigations liked 2D-Echo and TEE are becoming easily accessible for the patients and also are better intensive care unit services available so that management of patients with heart diseases with pregnancy should not be a big problem in the future.

Funding: No funding sources

Conflict of interest: None declared

Ethical approval: The study was approved by the Institutional Ethics Committee

\section{REFERENCES}

1. Surge D, Blake S, McDonald D. Pregnancy complicated by maternal heart disease at the National Maternity Hospital, Dublin; 1969-1978

2. Hameed A, Karaalp IS, Tummala PP, Wani OR, Canetti M, Akhter MW et al. The effect of valvular heart disease on maternal and fetal outcome of pregnancy. J Am College Cardiol. 2001;37(3):893-9.

3. Lupton M, Oteng-Ntim E, Ayida G, Steer PJ. Cardiac disease in pregnancy. Curr Opin Obstet Gynecol 2002,14(2):137-143

4. Fernando Arias, Shirish N Daftary, Amarnath G Bhide Practical guide to high-risk pregnancy and delivery. A South Asian Perspective 3rd Edition pg 511-512

5. Hiralal K. DC Dutta's Textbook of obstetrics 8th edition pg 319

6. Michel Peter "Experience of CHF in Pregnancy" $1874,2^{\text {nd }}$ edition 124:126

7. Angus MacDonald On the Bearing of Chronic Disease of the Heart Upon Pregnancy and Parturition"1877, $1^{\text {st }}$ edition 150:156
8. Avila WS1, Rossi EG, Ramires JA, Grinberg M, Bortolotto MR, Zugaib M, et al Pregnancy in patients with heart disease: experience with 1000 cases" Clin Cardiol. 2003;26(3):135-42

9. Oron G1, Hirsch R, Ben-Haroush A, Hod M, Gilboa $\mathrm{Y}$, Davidi $\mathrm{O}$, et al Pregnancy outcome in women with heart disease undergoing induction of labour BJOG 2004;111(7):669-75.

10. Michael de Swiet Editorial note Pregnancy and Heart Valve Replacement Int J Cardiol.1984;5(6):741-3.

11. Liang BL, Chen FR. Pregnancy after cardiac valve replacement: analysis of 21 cases. Zhonghua fu chan ke za zhi. 1993;28(7):386-8.

12. Weiss BM, von Segesser LK, Alon E, Seifert B, Turina MI. et al Outcome of cardiovascular surgery and pregnancy: a systematic review of the period 1984-1996 Am J Obstet Gynecol. 1998;179(6):164353

13. Jessup M, Brozena S Heart Failure N Engl J Med. 2003348(20):2007-18

14. Nassar AH1, Hobeika EM, Abd Essamad HM, Taher A, Khalil AM, Usta IM. Pregnancy outcome in women with prosthetic heart valves Am J Obstet Gynecol. 2004;191(3):1009-13

15. Fernando A, Amarnath B, Arulkumaran S, Kaizad D. Practical Guide to High Risk Pregnancy and Delivery 3rd Edition; A South Asian Perspective

16. K James, P J Steer, C P Weiner, B Gonik High Risk Pregnancy $3^{\text {rd }}$ Edition Saunders:1187-1188.

Cite this article as: Patel TL, Pandey KS, Ambaliya A. Study of cardiac disease and its outcome in pregnancy. Int J Reprod Contracept Obstet Gynecol 2019;8:262-6. 